\title{
Focus group methodology: some ethical challenges
}

\author{
Julius $\operatorname{Sim}^{1}$ (D) Jackie Waterfield ${ }^{2}$ (D)
}

Published online: 16 July 2019

(C) The Author(s) 2019

\begin{abstract}
Focus group methodology generates distinct ethical challenges that do not correspond fully to those raised by one-to-one interviews. This paper explores, in both conceptual and practical terms, three key issues: consent; confidentiality and anonymity; and risk of harm. The principal challenge in obtaining consent lies in giving a clear account of what will take place in the group, owing to unpredictability of the discussion and interaction that will occur. As consent can be seen in terms of creating appropriate expectations in the participant, this may therefore be hard to achieve. Moreover, it is less straightforward for the participant to revoke consent than in one-to-one interviews. Confidentiality and anonymity are potentially problematic because of the researcher's limited control over what participants may subsequently communicate outside the group. If the group discussion encourages over-disclosure by some participants, this problem becomes more acute. Harm in a focus group may arise from the discussion of sensitive topics, and this may be amplified by the public nature of the discussion. A balance should be struck between avoiding or closing down potentially distressing discussion and silencing the voices of certain participants to whom such discussion may be important or beneficial. As a means of addressing the above issues, we outline some strategies that can be adopted in the consent process, in a preliminary briefing session, during moderation of the focus group, and in a subsequent debriefing, and suggest that these strategies can be employed synergistically so as to reinforce each other.
\end{abstract}

Keywords Focus groups $\cdot$ Ethics $\cdot$ Consent $\cdot$ Confidentiality $\cdot$ Anonymity $\cdot$ Harm

\section{Introduction}

The ethics of interview research have been widely discussed. In contrast, ethical aspects of focus group research have received somewhat less detailed attention. Just as the methodology of dyadic interviews may raise ethical issues that do not correspond fully to those

Julius Sim

j.sim@keele.ac.uk

Jackie Waterfield

jwaterfield@qmu.ac.uk

1 School of Primary, Community and Social Care, Keele University, Staffordshire ST5 5BG, UK

2 School of Health Sciences, Queen Margaret University, Edinburgh EH21 6UU, UK 
raised by one-to-one interviews (Lowton 2018), so focus group methodology raises distinct challenges. This paper will examine these challenges, in both conceptual and practical terms, focusing on issues relating to consent, confidentiality, and risk of harm.

\subsection{Definition of a focus group}

The focus group has its origins in an approach to group interviewing described by Merton et al. (1956). Since then, it has gained increasing popularity within qualitative research and evaluation. A focus group can be defined broadly as 'a type of group discussion about a topic under the guidance of a trained group moderator' (Stewart 2018: p. 687). Agar and MacDonald (1995) suggest that a focus group lies somewhere between a meeting (reflecting the fact that it is specifically organized in advance and has a structure) and a conversation (reflecting the fact that the discussion has nonetheless a degree of spontaneity, with individuals picking up on one another's contributions). It is recommended that data collection, and subsequent analysis, should take account of both the dialogue and the interaction that has occurred within the group (Kitzinger 1994; Smithson 2000; Halkier 2010; Grønkjær et al. 2011), and seek to capture the way in which meaning is negotiated and coproduced in the group context (Wilkinson 1998). Several detailed accounts of focus group methodology are available (e.g., Morgan 1997; Hennink 2007; Krueger and Casey 2009; Carey and Asbury 2012; Barbour 2018).

\section{Consent}

Consent is a central ethical concern in research using human participants. Its specific importance in focus group research is suggested by Green and Hart's view of this method as one in which participants have a particular vulnerability, as they 'are not only persuaded by skilled facilitators to disclose intimate views, but also to do this in front of peers' (Green and Hart 1999: p. 31).

There are two models of consent: the mental model of consent sees it as the mental state of the person consenting, whereas the performative model sees it as the public act whereby such consent is communicated (Schnüriger 2018). On either interpretation, consent serves to legitimize the researcher's actions. Hence, Walker (2018: p. 131) takes consent to be a form of communication whereby 'an act that would have been impermissible for some reason is no longer impermissible for that reason.'

The underlying moral ground of consent is centred primarily in the notion of autonomy, on the basis that the consent process can be seen as a means of protecting and supporting autonomous decision making on the part of the research participant (Faden and Beauchamp 1986; Beauchamp 2009). Additionally, it is supported by the associated principle of respect for persons, which requires one not to use a person merely as a means to an end (Downie and Telfer 1969). Consent may be seen as having four essential elements: disclosure (the adequacy of the information given by the researcher); comprehension (the extent to which this information is understood by the participant); competence (the participant's cognitive or emotional capacity to give or withhold agreement); and voluntariness (the absence of inducement of coercion). Fulfilment of each of these elements is necessary for informed consent to carry its intended moral force (Sim 2010).

Lack of information-i.e., inadequate disclosure-is a constraint upon autonomous decision making (Beauchamp 1997). The onus is therefore on the researcher to provide 
a suitable type and quantity of information as a basis for the participant's choice. In interview-based studies, such information usually states the purpose of the study, gives an outline of the topic(s) to be covered, indicates the way in which the interview will be conducted and how long it is likely to last, draws attention to any potential benefits or risks associated with taking part, and describes what will be done with the data collected. Using the details provided, the participant should be able to foresee or imagine the situation to which he or she is consenting-therefore, the process is perhaps better seen as creating (or perhaps modifying) certain expectations in the mind of the participant rather than as simply the conveying of information. Such expectations will be formed by the manner and context in which information is communicated, and not just by the factual content of this information, and it is therefore more appropriate to think in terms of the message received in the consent process than in terms of the message sent.

\subsection{Disclosure and consent}

One potentially problematic issue relating to consent in focus groups stems from the degree of disclosure that is possible. In qualitative research generally, the fact that design and methods are to some extent emergent-rather than pre-specified, as they usually are in quantitative research-makes it hard to provide fine-grained detail on what will occur in a study (Wiles 2013). This applies even more in focus group research, because what takes place in the group depends in part upon other participants, who may spontaneously raise issues not necessarily intended, or predicted, by the moderator. As Warr (2005: p. 203) puts it, focus groups can be noisy 'as opinions and anecdotes are shared, challenged, and truncated as participants join in, or drop out of, the discussions taking place.' Furthermore, individual participants have less control than in a one-to-one interview. Although focus group participants can decline to respond to a particular question-probably more easily than in a one-to-one interview - they may not be able to divert the discussion away from a topic that they find uncomfortable. In effect, they may be unable to foreclose a particular topic in a way that is possible in an individual interview, particularly in the presence of more dominant group members. ${ }^{1}$ Accordingly, to the extent that the discussion in a focus group may take an unanticipated turn, reliance on the disclosure element of consent is thereby weakened.

Turning to the information that is disclosed, as noted earlier this will create particular expectations in participants. Some of these expectations may be inaccurate owing to certain assumptions on the part of participants. For example, they may not appreciate that whilst a focus group may be about exploring a social or health-related problem, it does not necessarily aim to provide solutions to such problems (Carey and Asbury 2012). Such a misconception may be encouraged by the 'consultative' feel of a group discussion, and the fact that focus groups are sometimes used in service evaluation and quality improvement projects (Smith et al. 1995; Schwarz et al. 2000). In this connection, for example, Briller et al. (2007-8) argue that it should be made clear to potential participants in a focus group on bereavement that they are not being invited to a support group.

\footnotetext{
1 It is commonly recommended that participants within a focus group should be homogeneous (Morgan 1997; Krueger and Casey 2009), so as to minimize differences in status or power and to prevent the discussion being dominated by higher-status members of the group. However, if such differences in status or power nonetheless occur, they may further limit the ability of some members to influence the discussion.
} 
A second issue arises here in relation to the contribution that the participant anticipates making to the group discussion. If the researcher obtains consent on the basis of seeking the participant's views, there is a responsibility to ensure that the individual has an opportunity to express these views, otherwise the expectation on which consent was based may not be realized. Ensuring that this expectation is fulfilled may require skilful moderation, so as to facilitate participation by all group members. Kitzinger (1995: p. 300) notes that within focus groups 'the articulation of group norms may silence individual voices of dissent'; however, the moderator may offset this tendency by encouraging contributions from such individuals (Smithson 2000). The other side of this coin is that participants should not feel obliged to contribute to a particular line of discussion, and again careful moderation is needed here. Lezaun (2007) characterizes an underlying principle of the focus group as isegoric - a concern to provide all participants with an equal opportunity to express (or to decline to express) their views. This obligation may be heightened by the expectations created in the consent process.

However, although participants may expect to have their voices heard, they should understand that the predominant insights that emerge from the focus group, and that are subsequently reported, may not reflect their individual views (especially if the issue is controversial, giving a rise to a range of possibly conflicting viewpoints). This is partly because it is not feasible to report each participant's views, and also because it is not the primary intention of a focus group to do so, given that whilst individual views may be voiced during the meeting, and may be tracked in the analysis (Finch and Lewis 2003), these are not readily separable from the interaction occurring within the group. Hence, the analytical focus centres on the co-production of perspectives in the group context, rather than on the perceptions of specific individuals: focus groups 'are not used to generate multiple accounts of individual perspectives' (Warr 2005: p. 201) and are not 'a collection of individual interviews with comments directed solely through the researcher' (Finch and Lewis 2003: p. 171).

A common practice in qualitative research based on interview data is respondent validation (Lincoln and Guba 1985). Its purpose is to allow research participants to review and comment on a transcript and/or the researcher's interpretation of it. In focus group research, however, a decision to provide a transcript to an individual participant entails also providing a written record of other participants' contributions, as it is hard to extract an individual account from the text in the transcript. Each participant would thereby be provided with a written record of the data provided by the whole group. This may not have been anticipated by other participants, and is therefore something of which they should be made aware in the consent process. Respondent validation would therefore be hard to carry out unless consented to by all participants.

\subsection{Consent as revocable}

Consent is normally regarded as revocable, such that an individual can withdraw from the study at any point after initially consenting to participate (Faden and Beauchamp 1986). It is important to consider the extent to which this option can realistically be exercised in a focus group. Withdrawing from a group discussion is a very public and potentially disruptive act that an individual may find hard to perform. Additionally, in consent documentation the right to withdraw is often stated in terms of not having to give a reason or justification for doing so- this would be difficult in a group situation, as leaving a collective social activity prematurely normally demands some form of explanation. Revoking consent 
to participation is thus less straightforward in a focus group than in many other research contexts.

This principle that consent is revocable may also be extended to an individual's data. Just as participants may withdraw their participation in an interview, it is claimed that they may similarly withdraw their data, either from the transcript, or from those parts that are reported as quotations, or from both (Kervin et al. 2006). ${ }^{2}$ A withdrawal of consent to the use of quotations presents fewer problems as regards the integrity of a study, as the insights arising from the analysis of the data concerned can still be reported, even though the researcher's choice of evidence to support them may be restricted. However, withdrawing data from a transcript prior to analysis - which is sometimes proposed (Farquhar 1999; Barbour 2018) — can give rise to particular difficulties in focus group research.

First, if data were to be removed from a transcript prior to analysis, notwithstanding the difficulty of doing so, the inferences that can be drawn from the transcript as a whole may be undermined. Meaning in focus group analysis is derived to a large degree from the dialogue that occurs between participants, rather than from what individual participants, taken singly, have said. The analytical insights that emerge are co-constructed by all the participants, and indeed by the moderator also. Thus, the removal of a section of dialogue may make it hard, or even impossible, to meaningfully interpret subsequent dialogue. Excising material from the transcript may therefore limit the extent to which a coherent analysis can occur.

Second, it follows from the preceding point that if the removal of one person's data adversely affects the insights that can be gained from a focus group, this affects the extent to which other participants' contributions to the discussion can play a part in the subsequent analysis. So not only does the withdrawal reduce the contribution of the person whose data they are, but it also denies other participants a full opportunity to make such a contribution.

Probably the only way to resolve this problem is to make it explicit in the consent process that whilst a participant can withdraw from the group, and may ask that his or her data are not quoted when the study is reported, withdrawing data prior to analysis is simply not possible. Accordingly, the inability to retract their data in this way is something to which participants will have consented. There might nonetheless be a concern that limiting individuals' ability to withdraw their data goes against the fundamental idea that consent is revocable, and thereby fails to respect their autonomy. So, it might be objected that autonomy implies the right to refuse, and that such refusal can occur at any stage in the research process. Three responses can be made to this objection. First, autonomy does not automatically imply that one may change one's mind. One can make an autonomous choice that one understands to be binding, such as when making a promise or signing a contract. Such a choice is not a sacrifice of autonomy-the commitment that it involves can be seen as an expression of one's autonomy. Second, given that other participants are likely to have consented to the focus group on the basis of having their views heard and contributing to what is gained from the subsequent analysis of the data, an attempt to respect one individual's

\footnotetext{
${ }^{2}$ In both cases, unless all dialogue in the focus group has been accurately ascribed to identifiable individuals - which may be challenging, given Warr's view (2005: p. 203) that focus group interaction may sometimes be 'disorderly and noisy' - it may not be possible to omit the data relating to any one such individual. Perhaps a more serious problem is that another's data could be removed by mistake.
} 
autonomous choice has the consequence of undermining such choice by others. ${ }^{3}$ Third, the detrimental effect on the analysis of withdrawing data in this way is liable to frustrate the moral obligation of the researcher to maximize the value of the insights gained from the study. Together, these three considerations may override what would otherwise be an obligation respect the participant's wishes. ${ }^{4}$

\section{Confidentiality and anonymity}

Confidentiality and anonymity are often treated more or less synonymously. ${ }^{5}$ There are, however, important distinctions that can be drawn between these two concepts, and the related notion of privacy. Confidentiality relates to what is done with information once it is in the researcher's possession, and specifically the extent to which it is disclosed to others. Anonymity, in contrast, is concerned with the attribution of information-can individuals be identified from the data that they provide or from other information relating to them? The fact that some individuals might be concerned about the disclosure of certain information even if they saw no possibility of its being attributed to them-or conversely, that they might not wish their identity as a participant to be disclosed even if no other information relating to them were revealed-demonstrates that confidentiality and anonymity are not equivalent. Whilst confidentiality and anonymity refer to the use and attribution of information, respectively, privacy has to do with initial access to information, and therefore comes into play before considerations of confidentiality and anonymity arise. ${ }^{6}$

As regards data, an assurance can be provided these will be reported anonymously, but if data are declared confidential this would seem to preclude their being directly reported in the form of quotations. Assurances of confidentiality in relation specifically to data are not therefore meaningful (unless anonymity is simply re-expressed in terms of the confidentiality of any identifying information). In terms of information other than data, such as information about the context of the study or biographical details relating to participants, both

\footnotetext{
3 A similar issue may arise with regard to the audio-recording of the group discussion. Hennink (2007: p. 36) suggests that participants should be told that they can ask for audio-taping equipment to be turned off at any time; any such request may not reflect the wishes of all participants.

4 In contrast, it might be argued that considerably more significant interests are at stake in terms of protecting a participant's anonymity, and it would therefore be much harder to justify opposing a request for quotations to be withheld from the report. It should also be noted that a refusal to withdraw data on the basis of what was stated by the researcher in the consent process requires that this message had been clearly explained and was understood.

5 For example: 'Participants need to be assured of the confidentiality and anonymity of their comments' (Hennink 2007: p. 41); 'participants must be guaranteed that they will not be identified by name or otherwise, referred to as anonymity or confidentiality' (Lincoln 2009: p. 152); 'The primary method researchers use to preserve anonymity and confidentiality is the use of pseudonyms for participants and also for the location of the research. In addition, other practices, such as changing the reported characteristics of participants (such as gender or occupation) are also used by some researchers to conceal identities and thereby maintain the confidentiality of the data provided by participants.' (Crow and Wiles 2008, p. 2); 'Confidentiality means we are obliged to protect each participant's identity, places and the location of the research' (Ryen 2016: p. 33).

6 Tolich (2016) argues against the usefulness of the concept of anonymity in qualitative research. However, he appears to construe anonymity solely in terms of what the researcher knows about the participant's identity, whereas the more pressing issue is what others know. In focus groups, and in qualitative research more generally, the core issue is not whether data are gathered anonymously from participants, but whether they are stored and presented anonymously.
} 
anonymity and confidentiality are feasible, as such information may either be presented in a form that preserves anonymity, or may not be disclosed at all (particularly if any such disclosure would be hard without thereby breaching anonymity). An important relationship between confidentiality and anonymity is that confidentiality is of greatest concern if anonymity cannot be assured.

The focus group is such that issues of confidentiality and anonymity are acute, especially when the discussion concerns sensitive topics:

The nature of the group setting is such that participants are obliged to express in public what they usually regard as private, and neither the reaction nor the discretion of the group can necessarily be predicted. (Wellings et al. 2000: p. 256)

\subsection{Deductive disclosure and internal confidentiality}

An obvious way to preserve anonymity is to ensure that no real names or other directly identifying information are reported. However, individual participants may be identified by other, indirect means through what is referred to as deductive disclosure: 'A narrative description of what an individual said to a researcher may, with a little collateral information, be sufficient to identify the individual [even] if no clear identifier, such as a name, is attached to the description' (Boruch et al. 1996: p. 161). Thus, even if nobody is named, it may be possible to link seemingly innocuous pieces of information together and determine a participant's identity, particularly in small and/or geographically circumscribed communities. A classic example of this is Carolyn Ellis's (1986) ethnographic study of two fishing villages in Chesapeake. Even though no directly identifying information had been used, it emerged that some participants in the study were able to identify themselves and others when the study was published (Ellis 1995). Two points about deductive disclosure bear emphasizing. First, the richer and more detailed the data reported, the greater the likelihood of deductive disclosure (Edwards and Weller 2016). Second, it may not be clear to the researcher, as an 'outsider', which information carries a risk of deductive disclosure; some reported details that appear to have no identifying potential may hold such meaning for others within the community or social group in which the research is centred.

In the context of focus groups, Tolich (2009) draws a distinction between internal and external confidentiality. Whereas external confidentiality concerns the possible disclosure of information by the researcher, internal confidentiality has to do with information that might be disclosed by members of the group. ${ }^{7}$ Clearly, external confidentiality can normally be assured by the researcher, as he or she is in control of what is reported from the study. Internal confidentiality relies on adherence to ground rules and observance of aspects of the consent process, over both of which the researcher has much more limited control.

It is often recommended that focus groups should be composed of individuals previously unknown to each other, so that pre-existing relationships, and certain assumptions or expectations that these involve, do not influence disclosure (Morgan 1997). This assists in preserving anonymity, but if participants are known to one another, their anonymity is

\footnotetext{
7 Rather confusingly, Tolich defines internal confidentiality in a different way in an earlier paper (Tolich 2004: p. 101), as: 'the ability for research subjects involved in the study to identify each other in the final publication of the research.' This interpretation is closer to the notion of deductive disclosure, and we will follow the definition offered in the later paper (Tolich 2009).
} 
clearly harder to maintain. ${ }^{8}$ Additionally, the discussion within the group-and therefore what may be reported-may make reference to existing relationships or a shared history within the group, such that individuals may be recognized by others outside the focus group but within a broader social circle, through deductive disclosure. Bloor et al. (2001: p. 25) suggest that the situation in which participants know one another may lead to a form of third-party breach of confidentiality, whereby a participant may 'make reference to a personal view or experience of another group member that that individual does not feel comfortable divulging within that particular group setting.' Kitzinger and Barbour (1999: p. 17) provide an example of such 'vicarious disclosure' when noting that in one focus group a participant indicated that another woman had worked as a prostitute. In groups where individuals are already known to one another, information disclosed—and any subsequent failure to observe confidentiality in respect of such information-may have a negative effect on participants' future relationships (Hofmeyer and Scott 2007).

A linked issue to internal confidentiality is that of over-disclosure. Within any form of interview, the rapport that is established between the informant and the researcher, and the efforts of the latter to encourage views or experiences to be expressed, may lead to an individual saying more than he or she might have wished or intended to. Within the specific context of a focus group, not only may the supportive atmosphere that can characterize the group encourage such over-disclosure (Bloor et al. 2001), ${ }^{9}$ but the group setting may make it less reparable than in a one-to-one interview. In particular, it is much harder to 'withdraw' a comment in the public context of a focus group than in a one-to-one interview (Carey and Asbury 2012). Morgan (1998: p. 91) suggests that over-disclosure may be more likely to occur in a focus group involving strangers- 'talking with someone you will never see again can lead to self-disclosure that goes beyond what you would tell your friends or family'-but also argues, in common with Frith (2000), that the consequences of over-disclosure may be more acute in a focus group in which some or all participants are known to one another, owing to its potential influence on their future relationships. Through careful monitoring of the dialogue and interaction occurring within the group, the moderator can help to minimize the risk of over-disclosure.

The moderator can also minimize deductive disclosure, by omitting certain information about participants in a report, by attributing quotations to categories of participants rather than pseudonymized individuals, or by altering other information that is potentially identifying. In the process, however, the ability of the researcher to present, or the reader to infer, valuable insights from the data may be reduced. Kaiser (2009: p. 1635) notes that 'unlike changing a specific name, changing additional details to render data unidentifiable can alter or destroy the original meaning of the data.' Moreover, if measures such as these are taken, it should not be automatically assumed that this is in accordance with participants' wishes. Whilst they may want their identity to be protected when a study is reported, they may nonetheless disapprove of the use of pseudonyms or categories, such as 'lone

\footnotetext{
8 A common means of preserving anonymity is to use pseudonyms or other anonymized identifiers. If participants in a focus group are hitherto unknown to one another, pseudonyms can be used within the group discussion (Wong, 2008); this anonymizes both the dialogue and the resulting transcript. Using pseudonyms in a focus group where participants are already acquainted effectively only serves to anonymize the transcript and may lead to a rather unnatural flow of dialogue. If data have not yet been anonymized, at the point of analysis pseudonyms or other anonymous identifiers can be substituted for real names, and these can be carried forward into the written research report.

${ }^{9}$ Guest et al. (2017) found that certain sensitive themes or personal disclosures were more likely in focus groups than in individual interviews.
} 
parent', that might invite negative stereotypes (Corden and Sainsbury 2006). Moreover, the unwillingness of some participants to use pseudonyms or to be anonymous may be a means of retaining 'ownership' of the meaning of their contributions to the data (Richards and Schwartz 2002). ${ }^{10}$ However, although acceding to a request not to use pseudonyms would respect the autonomous wishes of the individual(s) concerned, it might increase the likelihood of deductive disclosure in respect of other participants.

A further means by which anonymity can be protected is to eliminate written records of participants' true identities. Thus, in a focus group study of relationships between gay and bisexual men in the context of HIV infection and AIDS, O'Brien (1993) gained approval from an Institutional Review Board for the absence of signed consent forms. ${ }^{11}$

\section{Risk of harm}

Although in some respects focus groups offer a supportive environment to participants, the group context may also create a sense of public vulnerability:

In individual interviews respondents are protected by the relative intimacy and privacy of the interview situation. In a focus group session, in contrast, respondents are under pressure to perform (and possibly to conform) under the scrutiny of fellow participants. (Ransome 2013: p. 41)

This form of vulnerability may expose participants to various forms of harm. Thus, social or psychological harm may arise through a breach of confidentiality and/or anonymity. Information that is disclosed may lead to embarrassment, shame, stigmatization, discrimination, disruption of existing social relationships, or adverse employment consequences, and in some cases, participants may face legal action as a result of information that is made public (Warwick 1982).

However, harm may potentially arise in other ways than through breaches of confidentiality or anonymity. For example, as noted earlier, participants may mistake a focus group that aims to explore a particular problem for one that seeks to solve such a problem, with the result that unfulfillable hopes are raised and subsequently disappointed. Alternatively, the discussion of particularly sensitive issues within the group context may cause distress or embarrassment. In some situations, such feelings may be directly associated with the topic - such as in a focus group centred on issues to do with sexual behaviour-and may therefore be anticipated. Participants may therefore be considered to have foreseen this possibility when providing consent. Furthermore, as such feelings are likely to result from any discussion of the topic in question, the fact that such discussion occurs within a research context may not raise special concerns. In other instances, however, owing to the way in which the discussion evolves spontaneously, participants may experience distress or embarrassment that they did not predict. The researcher needs to judge whether this is

\footnotetext{
${ }^{10}$ Perry (2011) points out that, in some communities, the changing of names may have negative cultural associations. Writing about social research in Sudan, she notes that forced name-changing was historically a means of repressing minorities.

11 The focus in this section has been on the protection of confidentiality. In some circumstances, however, there may be a moral or legal obligation on researchers to breach confidentiality by disclosing certain information-e.g., a moral obligation to protect a third party from harm, or a legal obligation to report certain types of illegal activity (Bennett 2007). Such possibilities should, wherever possible, be included in the information given during the consent process.
} 
excessive or inappropriate. It is also important to note, however, that focus group discussions can provide a very supportive forum in which participants can express their emotions or anxieties, and thereby have a beneficial rather than a harmful effect. Thus, Ybarra et al. (2014) found that the use of online focus groups conducted with gay and bisexual adolescents on the topic of HIV prevention led to reduced feelings of isolation and a greater sense of support regarding decisions that some participants had made regarding abstinence. Again, the researcher needs to think carefully about the likely effects on the participants in the group.

Krueger and Casey (2009: p. xiii) maintain that focus group interviewing is 'about paying attention, being open to what people have to say and being nonjudgmental.' However, if participants express racist or other discriminatory views, the researcher should consider whether allowing such views to go unchallenged suggests complicity (Longhurst 2016). In a one-to-one interview such apparent acquiescence on the part of the researcher may reinforce the views of the individual concerned, but in a focus group it may additionally be construed as some form of public endorsement. In a similar way, harm may arise due to the expression of inaccurate information by a member of the group. The researcher may feel impelled to step out of the researcher role and intervene, or at least address the issue subsequently in a debrief. Hyde et al. (2005) and Wellings et al. (2000), for example, talk of the difficulty in staying silent in the face of factually incorrect comments in focus group discussions on HIV, and Kitzinger and Barbour (1999: p. 17) argue that one should not 'walk away from a group after having silently listened to people convincing each other that HIV can be transmitted by casual contact or that anal intercourse is safer than vaginal intercourse.'

There are two general approaches that the moderator can take in order to avoid or counteract discomfort or distress that may arise from the discussion of sensitive issues: (1) to seek to prevent such issues from arising in the first place, either by declaring them to be 'off limits' at the outset, or by averting them by steering the discussion in another direction; and (2) to try to minimize their impact when and if they do arise. The first of these approaches may seem an attractive solution. However, the issues concerned may be integral to the topic of the focus group, and avoiding them at the outset may, at least partly, frustrate the purpose of the research. Additionally, a strategy of avoidance may have the effect of denying certain individuals' participation. In discussing focus group research in areas related to sexuality, Kitzinger and Farquhar (1999) suggest that excluding discussion of sexual abuse, and failing to frame any questions on this topic, may marginalize participants who have had such experiences and convey an assumption that nobody could conceivably wish to discuss such issues in a public forum. In a similar way, Kleiber (2004: p. 93) maintains that 'it is important for the moderator to establish that no opinion or perspective is unacceptable' and Morgan (1992: p. 185) describes how the moderator can 'validate the expression of differences within the group.' The strategy proposed by Kitzinger and Farquhar (1999: p. 170) is that focus group moderators should try to ensure that discussion of sensitive issues is kept at an appropriate level, and 'should avoid using their power within the research setting either to close off sensitive possibilities or to push them too far.' Thus, a desire to avoid distress within focus groups-either by foreclosing certain topics at the beginning or by diverting the discussion when an issue arises-should be balanced against the risk of disenfranchising particular categories of individuals or censoring certain views as unacceptable.

The second approach — dealing with potential distress as it arises-relies on a prompt response on the part of the moderator. Owen (2001: p. 657) provides an example from her research on women's mental health problems: 
Whilst the women were permitted to discuss their painful and emotional experiences, the discussion was moved on if it was evident that the women were becoming distressed. As far as possible this was done sensitively by waiting for a suitable break in the self disclosure, openly acknowledging the woman's contribution, and posing another question to the group. More general questions were usually introduced at the end of each group in an attempt to lighten the atmosphere.

In some instances, distress can be prevented at an earlier stage, by managing the composition of the group. Thus, Bloor et al. (2001: p. 35) advise avoiding groups made up of 'individuals with such conflicting views that the resultant discussion might cause distress to individual members.' It would, however, be important to balance this strategy against the need to obtain whatever range of views is important for the aims of the research.

\subsection{Challenges in assessing harm}

Underlying assessment of the risk of harm are three fundamental difficulties. The first is that both predicting and identifying harm are not straightforward in qualitative social research. In medical research, by way of contrast, the nature of possible harms may be foreseen-for example, known complications or side-effects of a pharmacological or surgical intervention. Furthermore, such effects may be recognized promptly, as participants may be under prolonged observation or monitoring by clinicians who know what to look for. In qualitative research, however, whilst some potential harms may be obvious and predictable, foreseeing others might depend on knowledge of individual participants' psychological characteristics or biography-information that the researcher may not possess, at least initially. It is important for the researcher to be alert to both verbal and nonverbal signs of potentially harmful emotions (Kavanaugh and Ayres 1998). However, in some respects, harm may be less readily identified in a focus group than in a face-to-face interview: firstly, because the public context of the group may make participants less willing to display feelings of distress or embarrassment, and secondly because the moderator's attention is less closely focused on a particular participant than in a one-to-one interview.

The second difficulty springs from the fact that, as Wiles (2013) points out, apparently innocuous topics can unexpectedly cause some individuals distress, and as Hammersley and Traianou (2012) indicate, what is a harm to one person may be a benefit to another. This has particular relevance in a group setting. For example, if the discussion in a focus group were to turn to matters of bereavement or sexual harassment, this might cause distress to some participants who had had such experiences, but for others in the group with these experiences the discussion might be welcome, by virtue of providing an opportunity to express feelings that they are rarely able to share and to seek support or validation from others (Dyregrov 2004; Butler et al. 2018); a similar observation by Ybarra et al. (2014) was noted earlier. Madriz (1998: p. 116) refers to this notion of validation when discussing her research on fear of crime with Latina women, and suggests that focus groups may provide 'collective testimonies... [that] provide women with the possibility of breaking the wall of silence that has suppressed the expression of their ideas and emotions.' Similarly, avoiding reference to sexual orientation or gender identity may prevent discomfort to some group members, but for any who are members of the LGBT community this may eliminate 'the opportunity for the particular needs of those individuals to be identified' (Dodd 2009: p. 478). It should also be borne in mind that a focus group may draw on its own resources to limit potential harm (Kitzinger and Barbour 1999; Barbour 2018), especially if participants are previously known to one another and can enlist existing supportive relationships. 
The third difficulty is a conceptual one-that of distinguishing 'harm' from other unpleasant feelings and experiences, and thereby determining whether a moral wrong has been committed. ${ }^{12}$ Hitherto, we have used 'harm' in fairly broad sense. A more specific definition comes from Feinberg (1984: p. 34), who defines a harm as the 'thwarting, setting back, or defeating of an interest' (p. 33), where one's interests comprise 'all those things in which one has a stake.' Accordingly, '[o]ne person harms another... by invading, and thereby thwarting or setting back, his interest' (p. 34). These interests represent important aspects of a person's well-being. However, not everything that is disliked or gives rise to negative emotions is harmful. Here, Feinberg refers to what he calls offences:

Passing annoyance, disappointment, disgust, embarrassment, and various other disliked conditions such as fear, anxiety, and minor ("harmless") aches and pains, are not in themselves necessarily harmful. (Feinberg 1985: p. 1)

A harm, on these definitions, is clearly harder to justify morally than an offence. Indeed, an offence may promote rather than undermine a person's interest. If a discussion in a focus group causes a person to feel distress or embarrassment, this may be cathartic or lead to greater self-insight, which would presumably be in that person's interest. Thus, Hutchinson et al. (1994) and Cook and Bosley (1995) outline some of the psychological benefits that may potentially occur through participating in interview research, even on sensitive topics, and Hollway and Jefferson (2013: pp. 90-91) point to a psychoanalytical model of research whose theoretical principles:

stress that well-being depends on making the causes of distress conscious... According to this model, it is not necessarily harmful if research raises painful and distressing experience, though it may be discomforting.

Accordingly, it should not be assumed that all expressions of embarrassment, distress or other negative feelings within a focus group are necessarily harms and therefore a matter of moral concern. ${ }^{13}$

\subsection{Justifying harm}

A common means of justifying risk of harm in research is to point to a greater countervailing benefit that may likely be gained through a study. ${ }^{14}$ This rests upon the assumption that harms and benefits are commensurable, and thereby capable of being offset, the one against the other (Macintyre 1982). There are, however, a number of important caveats to this justification. First, the magnitude of some harms may be so great that no resulting benefits could justify them-though such harms might be very rare in social research (Diener and Crandall 1978). Second, steps must previously have been taken to minimize the risk of

\footnotetext{
12 Thus, on this definition to harm somebody is to wrong him or her, but to cause that person distress does not necessarily do so.

13 An additional question that we do not address here, for reasons of space, is causal responsibility for harm. Hammersley and Traianou (2012) provide a detailed discussion of this issue.

14 We used this argument earlier as part of our justification of resisting any requests for data to be withdrawn prior to analysis.
} 
harm, and it must be inherent to the topic and the nature of the research; risk of harm due to poor conduct of a study — such as insensitively worded questions or inattention to participants' emotional reactions - cannot be justified. Third, a precondition for any justification is that participants should have been informed about, and consented to, the possibility of harm (to the extent to which previously noted limitations of the consent process allow). The harms in question, if they occur, must be assumed by participants, not imposed upon them. For example, Iphofen (2009: p. 54) suggests that a possible social harm resulting from focus group participation might be that:

the time taken to invest, say, in attending a focus group... may lead to participants being unable to attend a regular social event in their community or family which is vital to their acceptance and/or status within that community.

If a justification were required for this, it might point to the participant's autonomous choice of one activity (the group discussion) over another (the social event).

Fourth, in addition to taking account of the relative magnitude of harms and benefits, these should also be weighed in probabilistic terms; using a remote chance of benefit to justify a likely risk of harm, other things being equal, would be questionable. Fifth, the type of harm and benefit should be considered. If a focus group study were to be carried out on aspects of self-harm in adolescents, the findings might have tangible medical or social benefits for adolescents in general, even if not necessarily for the specific participants in the study. Conversely, the same type of practical benefit might not be identifiable in a study on a topic where a more theoretical understanding is sought, yielding a more abstract value. Justifying a risk of harm in the second example might be harder than in the first. ${ }^{15}$

Finally, at a more conceptual level, such a weighing of harms against benefits-except when the harms and benefits affect the same individuals-relies to a large measure on an aggregate view; the fact that benefits, averaged across certain individuals, outweigh harms, averaged over other individuals, serves to justify these harms. Such a notion underlies Hennink's view that focus group researchers 'need to continually weight the potential social benefits of the information sought against the potential risk of harm to participants' (Hennink 2007: p. 38). A different view of the matter would suggest that the welfare of individuals cannot so readily be subsumed under considerations of overall social benefit, and would reject, or at least set limits to, such a trade-off between harms and benefits. This view would suggest that harms and benefits should be individuated-such that it matters whose harm it is and whose benefit it is, and these cannot readily be traded off between individuals. ${ }^{16}$

Thus, whilst harms and benefits may in principle be commensurable, they may less readily be aggregated across individuals. For example, a series of focus groups might be run with parents who had suffered the perinatal loss of a child. If it were anticipated that some participants might become acutely distressed, this might be justified if it were believed that such feelings might be cathartic for the individuals in question and assist in

\footnotetext{
15 Crucially, this is not to denigrate or underestimate the value of theoretical understanding, but merely to suggest that such benefit may have limited force in specific relation to the justification of risk of harm. See Hammersley and Traianou (2012) and Hammersley and Atkinson (2019) for a defence of the non-instrumental value of qualitative research.

16 The first line of moral reasoning outlined here is essentially a consequentialist one and the second essentially a deontological one (Scheffler 1982; Kamm 2013).
} 
the grieving process. The risk of harm would be balanced against the possibility of benefit for those same individuals. If, however, the justification rested upon future improvements in policy and practice in perinatal care-affecting future parents - the fact that harms and benefits would be distributed between, not within, individuals makes the process of justification more challenging.

\section{Practical strategies}

There are a number of ways in which the potentially problematic issues outlined hitherto can be avoided or mitigated, and some have already been touched upon. These strategies will be explored further in relation to the consent process, briefing prior to the focus group, the conduct and moderation of the focus group, and debriefing after the focus group.

The consent process: If the researcher provides information with a suitable level of detail and with due clarity, in principle this will help focus group participants to frame appropriate expectations of what will occur during the discussion. The purpose of the focus group can be explained and examples given of the sorts of questions that will be asked. Clarification can also be provided on what will be done with the data to be collected and the steps to be taken to preserve confidentiality and/ or anonymity. Thus, certain assurances can be given, though these can strictly only relate to those aspects of the focus group over which the researcher has a degree of influence (Carey and Asbury 2012). Morgan (1998) and Tolich (2009) provide suggested content for informed consent documentation.

Briefing: In addition to giving information in advance of a focus group, researchers normally discuss and negotiate a set of ground rules immediately prior to starting the discussion (Kevern and Webb 2001; Kleiber 2004; Breen 2006), especially in the case of sensitive topics (Farquhar 1999)—-though Krueger (1998: p. 23) suggests that using a less formal term than 'ground rules' may be helpful so as not to stifle discussion. The researcher can emphasize the public nature of a focus group and the need for confidentiality and anonymity, and provide guidance on subjects that might be felt unsuitable to be raised during the discussion, subject to the caveats discussed earlier. The briefing also allows participants' expectations of the group to be managed, for example by pointing out that the group seeks to discuss a particular health or social problem, not to provide a solution to such a problem. Importantly, the collective nature of the briefing allows the individual to reflect on his or her decision to take part in a situation that is closer than the formal consent process to the context of such participation. Furthermore, if at this point a participant has reconsidered the decision to take part in the study, the briefing can create an opportunity to withdraw less obtrusively than once the discussion has begun.

Conduct of the focus group: Although the moderator's influence over what happens in a focus group may be limited, he or she can nonetheless try to ensure that all members of the group have an opportunity to contribute to the discussion, without being under pressure to do so if unwilling, and that one or more individuals do not dominate the group. Additionally, the moderator can be alert to distress, breaches of confidentiality, or over-disclosure, and seek to turn the discussion in another direction 
if appropriate. ${ }^{17}$ If sensitive or emotionally difficult topics have been discussed, it may be helpful to finish the discussion on a more neutral or positive note (Finch and Lewis 2003; Briller et al. 2007-8). It is also important to ensure, when discussion of such sensitive topics is intended or anticipated, that the moderator can respond appropriately. Even if not qualified to provide psychological therapy, the moderator can offer emotional support (Rosenblatt 1995), and can take appropriate steps to ensure prompt access to qualified therapy through clinical referral (Carey and Asbury 2012).

Debriefing: After the focus group has finished, and its content summarized to participants, the moderator can reiterate key messages around confidentiality and anonymity, and clarify or comment upon any potentially sensitive or problematic issues that were raised during the discussion, where it was not appropriate to do so at the time. Participants can also be invited to discuss their reactions to such issues (Smith 1995). The moderator can stay in the room for a while at the end of the focus group, or otherwise make him- or herself available, to give individual participants the opportunity to address any issues or concerns (Bloor et al. 2001; Sherriff et al. 2014).

The first two of the above approaches - the process of obtaining consent and the briefing prior to the discussion - are means of providing information and giving certain assurances as to what is and what is not intended or foreseen. Martin Tolich, however, is pessimistic regarding the researcher's ability to provide assurances to focus group participants:

...let the researcher, the participants and the ethics committee beware that the only ethical assurance that can be given to focus group participants is that there are few ethical assurances. (Tolich 2009: p. 99)

He acknowledges the role of the moderator, but suggests that one should not rely unduly on the moderator's skill in controlling the group, and has similar reservations regarding the use of ground rules or a debriefing session. Instead, Tolich's central strategy is one of 'caveat emptor':

Taking part in focus groups involves risk and the participants' [sic] must have these risks identified for them, explicitly, and then be willing to absorb those risks. (Tolich 2009: p. 106) ${ }^{18}$

In Tolich's approach to the ethics of focus groups, the principal emphasis is accordingly on the quality of the consent process and participants' autonomous assumption of certain risks, rather than on measures to mitigate ethical problems as they arise:

Ethical assurances, rather than safety techniques, should be at the fore. These assurances should be communicated to the potential participant in the recruitment phase of the research with such transparency that they allow the research participant to read in advance how the researcher plans to contend with the two endemic ethical flaws [relating to confidentiality and consent] in focus group research. Transparency is manifest in both an explicit description of the endemic flaws and

\footnotetext{
${ }^{17}$ Seymour et al. (2002) describe how presenting potentially sensitive topics in a PowerPoint presentation assisted the moderator in switching the group's focus if the discussion became deeply personal.

${ }^{18} \mathrm{He}$ reflects this view in the information that he proposes as part of the consent documentation provided to participants: 'There are risks in taking part in focus group research and taking part assumes that you are willing to assume those risks' (Tolich 2009: p. 103).
} 
an honest statement on the limitations of any ethical assurances. (Tolich 2009: p.

106)

On this basis, Tolich provides detailed suggestions as to the information that should be included in an informed consent form, building on earlier suggestions by Morgan (1998).

However, as a general strategy, it may be unwise to rely so heavily on the consent process as a means of addressing ethical challenges in focus groups. First, as an empirical issue, providing information to participants as part of the consent process is only of value if this information is understood and recalled, and if it creates appropriate expectations of what will take place in the focus group. However, as noted earlier, the specific issues that are discussed in a focus group, and the way in which participants interact and behave during the discussion, are to a large degree unpredictable, and participants' expectations based on prior information may not be realized. Moreover, whilst its generalizability to social research may be questioned, evidence from the medical literature of poor recall and comprehension of consent information may caution us against over-reliance on some aspects of the consent process (Corrigan 2003; Dawson 2009). Second, at a more philosophical level, whilst consent may be a necessary condition for involving an individual in a study, it is not a sufficient condition - the researcher's moral responsibility does not end with ensuring that participants make an informed and autonomous choice as regards participation. The focus group participant may well consent to the possibility of distress during the discussion or the risk of a breach of confidentiality, but there are separate obligations on the part of the researcher-based on an independent notion of non-maleficence-to mitigate such risks as the discussion takes place. If these obligations are not discharged, the involvement of the participant may be morally unjustified, regardless of the apparent quality of the consent process.

A more effective approach, perhaps, is to enlist all four of the strategies outlined above in approximately equal measure, so that one strategy may reinforce, or compensate for, another in a synergistic manner. In this way, the pre-discussion briefing can reiterate and re-emphasize information given in an information sheet as part of the consent process, and address any questions that may have subsequently arisen in participants' minds. The briefing can also raise issues regarding the conduct of the group - including ground rules- that might be less effectively conveyed by an information sheet. Moreover, such ground rules may be more effective if mutually negotiated by the group, rather than being stated in the consent documentation. Similarly, raising such issues at the level of the group, as opposed to when raised at an individual level in the consent process, may place them more clearly in the context to which they apply.

The process of moderation can attempt to deal with sensitive and potentially distressing issues that arise-perhaps unpredictably-through the dynamics of the interaction within the focus group. For example, Owen (2001) relates an incident in which a woman unexpectedly gave an account of her partner's suicide and her feelings of loss and betrayal, and Seymour et al. (2002: p. 523) relate an incident in a focus group on end-of-life care where a woman stated 'I've done euthanasia' - in both cases the moderator felt the need to take action to deal with the situation. If appropriate, at certain junctures in the discussion the moderator can also give reminders of matters of confidentiality outlined in the consent documentation and encourage observance of agreed ground rules. Finally, a debriefing after the group discussion can not only reinforce elements within each of the previous strategies, but may also provide an opportunity for individual participants to raise concerns that may have been difficult to address during the group discussion. 


\section{Conclusion}

In this paper we have attempted to identify and analyse some of the principal ethical issues that may arise within focus group research, and suggest practical approaches to managing these issues. Many of these issues stem from, or are given a particular emphasis by, the nature of focus group methodology. Thus, the spontaneous and at least partially unpredictable nature of the dialogue between participants may give rise to problems to do with harm or confidentiality, and also limits the extent to which such problems can be identified in advance during the consent process. The dynamics within the group may lead to some individuals dominating the discussion and thereby denying the expression of others' views. The group context also complicates matters by creating multiple, intersecting interests. What may cause distress to one participant may give voice to, or provide a sense of validation to, another participant. Similarly, steps taken to protect anonymity or confidentiality in respect of some participants may undermine the contribution of others. Further issues arise when a focus group takes place within the context of existing social or professional relationships.

Some of the ethical challenges posed by focus groups can be addressed through the consent process, provided that appropriate expectations have been expressed and received, but steps should also be taken to supplement and reinforce these issues closer to the actual context of the focus group: in a briefing immediately prior to the discussion, during the discussion itself, and in a debriefing immediately after the focus group. However, the dynamic context of the focus group demands more than this. The moderator needs to make on-thespot judgements; for example, on whether or not some individuals are at risk of harm from the nature of the discussion taking place, or on whether a particular topic can be closed down without thereby depriving some participants of their voice.

Open Access This article is distributed under the terms of the Creative Commons Attribution 4.0 International License (http://creativecommons.org/licenses/by/4.0/), which permits unrestricted use, distribution, and reproduction in any medium, provided you give appropriate credit to the original author(s) and the source, provide a link to the Creative Commons license, and indicate if changes were made.

\section{References}

Agar, M., MacDonald, J.: Focus groups and ethnography. Hum. Organ. 54(1), 78-86 (1995)

Barbour, R.: Doing Focus Groups, 2nd edn. Sage Publications, London (2018)

Beauchamp, T.L.: Informed consent. In: Veatch, R.M. (ed.) Medical Ethics, 2nd edn, pp. 185-208. Jones and Bartlett, Boston (1997)

Beauchamp, T.L.: Autonomy and consent. In: Miller, F., Wertheimer, A. (eds.) The Ethics of Consent: Theory and Practice, pp. 55-78. Oxford University Press, Oxford (2009)

Bennett, R.: Confidentiality. In: Ashcroft, R.E., Dawson, A., Draper, H., McMillan, J.R. (eds.) Principles of Health Care Ethics, 2nd edn, pp. 325-332. Wiley, Chichester (2007)

Bloor, M., Frankland, J., Thomas, M., Robson, K.: Focus Groups as Social Research. Sage, London (2001)

Boruch, R.F., Dennis, M., Cecil, J.S.: Fifty years of empirical research on privacy. In: Stanley, B.H., Sieber, J.E., Melton, G.B. (eds.) Research Ethics: A Psychological Approach, pp. 129-173. University of Nebraska Press, Lincoln (1996)

Breen, R.L.: A practical guide to focus-group research. J. Geogr. High. Educ. 30(3), 463-475 (2006)

Briller, S.H., Schim, S.M., Meert, K.L., Thurston, C.S.: Special considerations in conducting bereavement focus groups. Omega 56(3), 255-271 (2007-8)

Butler, A.E., Hall, H., Copnell, C.: Bereaved parents' experiences of research participation. BMC Palliat. Care 17, 122 (2018) 
Carey, M.A., Asbury, J.-E.: Focus Group Research. Left Coast Press, Walnut Creek (2012)

Cook, A.S., Bosley, G.: The experience of participating in bereavement research: stressful or therapeutic? Death Stud. 19(2), 157-170 (1995)

Corden, A., Sainsbury, R.: Exploring 'quality': research participants' perspectives on verbatim quotations. Int. J. Soc. Res. Methodol. 9(2), 97-110 (2006)

Corrigan, O.: Empty ethics: the problem with informed consent. Sociol. Health Illn. 25(3), 768-792 (2003)

Crow, G., Wiles, R.: Managing anonymity and confidentiality in social research: the case of visual data in community research: NCRM Working Paper Series 8/08. ESRC National Centre for Research Methods, Southampton (2008)

Dawson, A.: The normative status of the requirement to gain an informed consent in clinical trials: comprehension, obligations and empirical evidence. In: Corrigan, O., McMillan, J., Liddell, K., Richards, M., Weijer, C. (eds.) The Limits of Consent: A Socio-ethical Approach to Human Subject Research in Medicine, pp. 99-113. Oxford University Press, Oxford (2009)

Diener, E., Crandall, R.: Ethics in Social and Behavioural Research. Chicago University Press, Chicago (1978)

Dodd, S.-J.: LGBTQ: protecting vulnerable subjects in all studies. In: Mertens, D.M., Ginsberg, P.E. (eds.) The Handbook of Social Research Ethics, pp. 474-488. Sage Publications, Thousand Oaks (2009)

Downie, R.S., Telfer, E.: Respect for Persons. George Allen \& Unwin, London (1969)

Dyregrov, K.: Bereaved parents' experience of research participation. Soc. Sci. Med. 58(2), 391-400 (2004)

Edwards, R., Weller, S.: Ethical dilemmas around confidentiality and anonymity in longitudinal research data sharing: the death of Dan. In: Tolich, M. (ed.) Qualitative Research Ethics in Practice, pp. 97-108. Routledge, London (2016)

Ellis, C.: Fisher Folk: Two Communities on Chesapeake Bay. University Press of Kentucky, Lexington (1986)

Ellis, C.: Emotional and ethical quagmires in returning to the field. J. Contemp. Ethnogr. 24(1), 68-98 (1995)

Faden, R.R., Beauchamp, T.L.: A History and Theory of Informed Consent. Oxford University Press, New York (1986)

Farquhar, C.: Are focus groups suitable for 'sensitive' topics? In: Barbour, R.S., Kitzinger, J. (eds.) Developing Focus Group Research: Politics, Theory and Practice, pp. 47-63. Sage Publications, London (1999)

Feinberg, J.: The Moral Limits of the Criminal Law, Volume 1: Harm to Others. Oxford University Press, Oxford (1984)

Feinberg, J.: The Moral Limits of the Criminal Law, Volume 2: Offense to Others. Oxford University Press, Oxford (1985)

Finch, H., Lewis, J.: Focus groups. In: Ritchie, J., Lewis, J. (eds.) Qualitative Research Practice: A Guide for Social Science Students and Researchers, pp. 170-198. Sage Publications, London (2003)

Frith, H.: Focusing on sex: using focus groups in sex research. Sexualities 3(3), 275-297 (2000)

Green, J., Hart, L.: The impact of context on data. In: Barbour, R.S., Kitzinger, J. (eds.) Developing Focus Group Research: Politics, Theory and Practice, pp. 21-35. Sage Publications, London (1999)

Grønkjær, M., Curtis, T., de Crespigny, C., Delmar, C.: Analysing group interaction in focus group research: impact on content and the role of the moderator. Qual. Stud. 2(1), 16-30 (2011)

Guest, G., Namey, E., Taylor, J., Eley, N., McKenna, K.: Comparing focus groups and individual interviews: findings from a randomized study. Int. J. Soc. Res. Methodol. 20(6), 693-708 (2017)

Halkier, B.: Focus groups as social enactments: integrating interaction and content in the analysis of focus group data. Qual. Res. 10(1), 71-89 (2010)

Hammersley, M., Atkinson, P.: Ethnography: Principles in Practice, 4th edn. Routledge, Abingdon (2019)

Hammersley, M., Traianou, A.: Ethics in Qualitative Research: Controversies and Contexts. Sage Publications, London (2012)

Hennink, M.M.: International Focus Group Research: A Handbook for the Health and Social Sciences. Cambridge University Press, Cambridge (2007)

Hofmeyer, A.T., Scott, C.M.: Moral geography of focus groups with participants who have pre-existing relationships in the workplace. Int. J. Qual. Methods 6(2), 69-79 (2007)

Hollway, W., Jefferson, T.: Doing Qualitative Research Differently: A Psychosocial Approach, 2nd edn. Sage Publications, London (2013)

Hutchinson, S.A., Wilson, M.E., Wilson, H.S.: Benefits of participating in research interviews. Image J. Nurs. Sch. 26(2), 161-166 (1994)

Hyde, A., Howlett, E., Brady, D., Drennan, J.: The focus group method: insights from focus group interviews on sexual health with adolescents. Soc. Sci. Med. 61(12), 2588-2599 (2005)

Iphofen, R.: Ethical Decision-Making in Social Research: A Practical Guide. Macmillan, Houndmills (2009) 
Kaiser, K.: Protecting respondent confidentiality in qualitative research. Qual. Health Res. 19(11), 16321641 (2009)

Kamm, F.M.: Nonconsequentialism. In: LaFollette, H., Persson, I. (eds.) The Blackwell Guide to Ethical Theory, 2nd edn, pp. 261-286. Wiley Blackwell, Chichester (2013)

Kavanaugh, K., Ayres, L.: "Not as bad as it could have been": assessing and mitigating harm during research interviews on sensitive topics. Res. Nurs. Health 21(1), 91-97 (1998)

Kervin, L., Vialle, W., Herrington, J., Okely, T.: Research for Educators. Thomson/Social Science Press, South Melbourne (2006)

Kevern, J., Webb, C.: Focus groups as a tool for critical social research in nurse education. Nurse Educ. Today 21(4), 323-333 (2001)

Kitzinger, J.: The methodology of focus groups: the importance of interaction between research participants. Sociol. Health Illn. 16(1), 103-121 (1994)

Kitzinger, J.: Introducing focus groups. Brit. Med. J. 311(7000), 299-302 (1995)

Kitzinger, J., Barbour, R.S.: Introduction: the challenge and promise of focus groups. In: Barbour, R.S., Kitzinger, J. (eds.) Developing Focus Group Research: Politics, Theory and Practice, pp. 1-20. Sage Publications, London (1999)

Kitzinger, J., Farquhar, C.: The analytical potential of 'sensitive moments' in focus group discussions. In: Barbour, R.S., Kitzinger, J. (eds.) Developing Focus Group Research: Politics, Theory and Practice, pp. 156-172. Sage Publications, London (1999)

Kleiber, P.B.: Focus groups: more than a method of qualitative inquiry. In: deMarrais, K.B., Lapan, S. (eds.) Foundations for Research: Methods of Inquiry in Education and the Social Sciences, pp. 87-102. Routledge, New York (2004)

Krueger, R.A.: Moderating Focus Groups. Sage Publications, Thousand Oaks (1998)

Krueger, R.A., Casey, M.A.: Focus Groups: A Practical Guide for Applied Research, 4th edn. Sage Publications, Thousand Oaks (2009)

Lezaun, J.: A market of opinions: the political epistemology of focus groups. Sociol. Rev. 55(2 suppl), 130-151 (2007)

Lincoln, Y.S.: Ethical practices in qualitative research. In: Mertens, D.M., Ginsberg, P.E. (eds.) The Handbook of Social Research Ethics, pp. 150-169. Sage Publications, Thousand Oaks (2009)

Lincoln, Y.S., Guba, E.G.: Naturalistic Inquiry. Sage Publications, Newbury Park (1985)

Longhurst, R.: Semi-structured interviews and focus groups. In: Clifford, N., Cope, M., Gillespie, T., French, S. (eds.) Key Methods in Geography, pp. 143-156. Sage Publications, Thousand Oaks (2016)

Lowton, K.: He said, she said, we said: ethical issues in conducting dyadic interviews. In: Iphofen, R., Tolich, M. (eds.) The SAGE Handbook of Qualitative Research Ethics, pp. 133-147. Sage Publications, London (2018)

Macintyre, A.: Risk, harm and benefit assessments as instruments of moral evaluation. In: Beauchamp, T.L., Faden, R.R., Wallace, R.J., Walters, L. (eds.) Ethical Issues in Social Science Research, pp. 175-189. Johns Hopkins University Press, Baltimore (1982)

Madriz, E.I.: Using focus groups with lower socioeconomic status Latina women. Qual. Inq. 4(1), 114128 (1998)

Merton, R.K., Fiske, M., Kendall, P.L.: The Focused Interview: A Manual of Problems and Procedures. Free Press, Glencoe (1956)

Morgan, D.L.: Designing focus group research. In: Stewart, M., Tudiver, F., Bass, M.J., Dunn, E.V., Norton, P.G. (eds.) Tools for Primary Care Research, pp. 177-193. Sage Publications, Newbury Park (1992)

Morgan, D.L.: Focus Groups as Qualitative Research, 2nd edn. Sage Publications, Thousand Oaks (1997)

Morgan, D.L.: The Focus Group Guidebook. Sage Publications, Thousand Oaks (1998)

O’Brien, K.: Improving survey questionnaires through focus groups. In: Morgan, D.L. (ed.) Successful Focus Groups: Advancing the State of the Art, pp. 105-117. Sage Publications, Newbury Park (1993)

Owen, S.: The practical, methodological and ethical dilemmas of conducting focus groups with vulnerable clients. J. Adv. Nurs. 36(5), 652-658 (2001)

Perry, K.H.: Ethics, vulnerability, and speakers of other languages: how university IRBs (do not) speak to research involving refugee participants. Qual. Inq. 17(10), 899-912 (2011)

Ransome, P.: Ethics and Values in Social Research. Palgrave Macmillan, Houndmills (2013)

Richards, H.M., Schwartz, L.J.: Ethics of qualitative research: are there special issues for health services research? Fam. Pract. 19(2), 135-138 (2002)

Rosenblatt, P.C.: Ethics of qualitative interviewing with grieving families. Death Stud. 19(2), 139-155 (1995)

Ryen, A.: Research ethics and qualitative research. In: Silverman, D. (ed.) Qualitative Research, pp. 31-46. Sage Publications, Thousand Oaks (2016) 
Scheffler, S.: The Rejection of Consequentialism: A Philosophical Investigation of the Considerations Underlying Rival Moral Conceptions. Clarendon Press, Oxford (1982)

Schnüriger, H.: What is consent? In: Müller, A., Schaber, P. (eds.) The Routledge Handbook of the Ethics of Consent, pp. 21-31. Routledge, Oxford (2018)

Schwarz, M., Landis, S.E., Rowe, J.E., Janes, C.L., Pullman, N.: Using focus groups to assess primary care patients' satisfaction. Eval. Health Prof. 23(1), 58-71 (2000)

Seymour, J., Bellamy, G., Gott, M., Ahmedzai, S.H., Clark, D.: Using focus groups to explore older people's attitudes to end of life care. Ageing Soc. 22(4), 517-526 (2002)

Sherriff, N., Gugglberger, L., Hall, C., Scholes, J.: "From start of finish": practical and ethical considerations in the use of focus groups to evaluate sexual health service interventions for young people. Qual. Psychol. 1(2), 92-106 (2014)

Sim, J.: Conflicts in research ethics: consent and risk of harm. Physiother. Res. Int. 15(2), 80-87 (2010)

Smith, J.A., Scammon, D.L., Beck, S.L.: Using patient focus groups for new patient services. Jt. Comm. J. Qual. Improv. 21(1), 22-31 (1995)

Smith, M.W.: Ethics in focus groups: a few concerns. Qual. Health Res. 5(4), 478-486 (1995)

Smithson, J.: Using and analysing focus groups: limitations and possibilities. Int. J. Soc. Res. Methodol. 3(2), 103-119 (2000)

Stewart, D.W.: Focus groups. In: Frey, B.B. (ed.) The SAGE Encyclopedia of Educational Research, Measurement, and Evaluation, vol. 2, pp. 687-692. Sage Publications, Thousand Oaks (2018)

Tolich, M.: Internal confidentiality: when confidentiality assurances fail relational informants. Qual. Sociol. 27(1), 101-106 (2004)

Tolich, M.: The principle of caveat emptor: confidentiality and informed consent as endemic ethical dilemmas in focus group research. Bioeth. Inq. 6(1), 99-108 (2009)

Tolich, M.: Are qualitative research ethics unique? In: Tolich, M. (ed.) Qualitative Research Ethics in Practice, pp. 33-47. Routledge, London (2016)

Walker, T.: Consent and autonomy. In: Müller, A., Schaber, P. (eds.) The Routledge Handbook of the Ethics of Consent, pp. 131-139. Routledge, Oxford (2018)

Warr, D.J.: "It was fun... but we don't usually talk about these things": analyzing sociable interaction in focus groups. Qual. Inq. 11(2), 200-225 (2005)

Warwick, D.P.: Types of harm in social research. In: Beauchamp, T.L., Faden, R.R., Wallace, R.J., Walters, L. (eds.) Ethical Issues in Social Science Research, pp. 101-124. Johns Hopkins University Press, Baltimore (1982)

Wellings, K., Branigan, P., Mitchell, K.: Discomfort, discord and discontinuity as data: using focus groups to research sensitive topics. Cult. Health Sex. 2(3), 255-267 (2000)

Wiles, R.: What are Qualitative Research Ethics? Bloomsbury, London (2013)

Wilkinson, S.: Focus groups in feminist research: power, interaction, and the co-production of meaning. Women's Stud. Int. Forum 21(1), 111-125 (1998)

Wong, L.P.: Focus group discussion: a tool for health and medical research. Singap. Med. J. 49(3), 256-261 (2008)

Ybarra, M.L., DuBois, L.Z., Parsons, J.T., Prescott, T.L., Mustanski, B.: Online focus groups as an HIV prevention program for gay, bisexual, and queer adolescent males. AIDS Educ. Prev. 26(6), 554-564 (2014)

Publisher's Note Springer Nature remains neutral with regard to jurisdictional claims in published maps and institutional affiliations. 